\title{
The frequency of buying cured meat products in the context of consumers' store choices
}

\author{
Aleksandar Grubor $^{1}$, Nikola Milicevic ${ }^{1, *}$, and Nenad Djokic ${ }^{1}$ \\ ${ }^{1}$ University of Novi Sad, Faculty of Economics in Subotica, Department for trade, marketing and \\ logistics, 24000 Subotica, Republic of Serbia
}

\begin{abstract}
Research background: In the sector of cured meat production and sale, companies are struggling to attract as many consumers as possible. Because of this, special attention should be dedicated to the examination of consumer behavior towards cured meat products. In relation to this, there are studies, including different types of factors, such as geographic, economic and socio-demographic. In this paper, consumer behavior regarding cured meat products was investigated from the aspect of consumers' store choices.

Purpose of the article: The paper examines the frequency of buying cured meat products on a monthly basis, taking into account factors that influence consumers store choices. Based on the buying frequency, all respondents have been divided into low, medium and high frequency segments, which were compared in relation to store choosing factors.

Methods: The research was conducted on a sample that included 449 respondents from the city of Novi Sad. They were interviewed in 2019, by the use of a specially designed questionnaire. For processing the data, one way ANOVA and Tukey post-hoc test were implemented.

Findings \& Value added: The obtained results have shown that the largest percent of respondents - nearly $60 \%$ - belong to medium frequency segment, followed by high frequency segment (about one third of respondents) and low frequency segment (less than 10\%). The closeness to place of living, appropriate working hours, wide assortment, quality of products and favorable prices belong to the top 5 most influential factors in each of the segments. These findings can be used by manufacturers and retailers when making decisions regarding production and marketing activities.
\end{abstract}

Keywords: cured meat; buying frequency; consumer behaviour; store choices

JEL Classification: $M 30 ; M 31$ 


\section{Introduction}

In many countries, meat represents an important item of nutrition for most people. Although, its consumption is on a high level in the developed regions, the demand for meat is still increasing, bearing in mind that it is becoming more accessible in some countries [1]. Hereby, because the growth and the level of population are higher in developing regions contrary to developed ones, the growth rate of meat consumption is also expected to be higher in developing regions [1]. However, despite the increase of a growth rate, large differences are still present in the consumption of meat between regions. Thus, while meat consumption per capita in Africa for 2016-18, was below 20kg/person/year, in Europe and North America, it was over 60 and $80 \mathrm{~kg} /$ person/year, respectively [1].

Besides its direct use, meat can be processed to obtain different types of products. Following Clonan et al. [2, p. 367-368], "processed meat includes meat products that have been modified to change the taste or extend shelf life through curing, smoking, salting or adding preservatives". Depending on whether they contain nitrite or nitrate, there is a difference between "cured" and "uncured" meat products [3]. Therefore, while the former (cured meat) includes nitrate/nitrite in any form, the later (uncured meat) does not.

Because of their importance for human nutrition and economy in general, there are many researches related to meat and meat products. Some of them are associated to consumer behaviour, including different kinds of variables, such as consumers' sociodemographic characteristics [4] or their attitudes [5].

There is also a number of studies in which the attention was dedicated to the quality aspect. In accordance to Issanchou [6], factors relevant for perceived meat quality are related to convenience, animal welfare, safetiness and healthiness. When it comes to convenience, the emphasis should be put on the speed and efforts needed for food preparation, especially bearing in mind that consumers are more interested in products that are faster and easier to prepare. As concerns associated to animal welfare can affect the production and consumption of meat products, this factor should also be considered as an important determinant of meat purchase intention. Regarding safetiness, there is always a little concern of consumers, which does not have to rest on scientific or medical evidence. Thus, besides objective safety, meat quality depends on the perceived safety as well. Beliefs related to healthiness are also based on different kind of information, which can be provided from magazines, friends or nutritionists. In addition to mentioned factors, Issanchou [6] discusses intrinsic quality cues, extrinsic quality cues and sensory factors.

Espejel et al. [7] also examined the perceived quality of two food products, among which was the air-cured ham. Hereby, they analyzed the effects of intrinsic and extrinsic perceived quality attributes on consumer satisfaction and loyalty, including the relations with the purchasing intention. When it comes to the air-cured ham, contrary to intrinsic, extrinsic perceived quality significantly influenced satisfaction and loyalty. Moreover, satisfaction significantly influenced loyalty, while purchasing intention was significantly affected by both, satisfaction and loyalty.

Besides the attributes related to product quality, in certain researches the analyses included the factors related to a retailer. $\mathrm{Hu}$ [8] investigated choices of Chinese consumers among meat stores, by implementing a model that included several store attributes. According to their results, significant negative weight was obtained for price attribute. Negative coefficients were obtained for supermarket and wholesale market attributes, as well, indicating that Chinese consumers are less likely to select these shopping places, compared to wet markets. Significant and positive coefficients were recorded for quality and location variables, suggesting that consumers opt for stores which offer higher quality of meat, and stores which provide convenient access. Opposite to those variables, attributes 
associated to store service level and the availability of different types of meat products were not significant.

Regarding the choice of a store for buying meat products, Souček and Turčínková [9] examined several factors that influence consumers' decisions. The results pointed that, in addition to factors related to product quality (fresh products and quality of merchandise), some store-related factors, such as cleanliness and store layout, easy orientation inside the store, short waiting times at cash registers and fast service and care, were also significant for consumers when selecting the store. Among the others, Souček and Turčínková [9] found four basic cluster groups: price and habits, in-store situational factors, qualitative store attributes and shopping convenience.

In the research, conducted by Lavanya et al. [10], interrelationships between three constructs (service quality, consumer satisfaction and consumer loyalty) were analyzed in relation to the retail store which sold chilled chicken and meat products. Following their study, retail service quality, which included five dimensions (reliability, policy, problem solving, physical appearance and personal interaction), affected consumer satisfaction and loyalty. In regard to the relation between consumer satisfaction and loyalty, as Lavanya et al. [10] stated, their findings pointed that consumer loyalty depended not only on satisfaction, but on some other factors as well.

Similar to previous studies, in this paper, the attention was also dedicated to consumer behaviour towards meat products, taking into account factors related to consumers store choices. Hereby, the emphasis was on the frequency of buying cured meat products on a monthly basis. The obtained results could be of a great help to both, manufacturers and retailers, especially when it comes to decisions related to their marketing activities. After the introduction part, methodology section is presented, followed by the results and discussion.

\section{Methodology}

\subsection{Sample}

Convenience sampling method was used. The total of 449 respondents from the city of Novi Sad (aged 25 to 65) were interviewed in April 2019. There was a precondition for a person to become a respondent - he or she needed to buy cured meat for household and / or to decide on such purchases.

The sample consists of $41.9 \%$ men and $58.1 \%$ women, with the average age of 43.23 years (standard deviation 12.02).

\subsection{Questionnaire}

The instrument was created for a wider research (in comparison to the research presented in this paper) regarding purchases of cured meat products on the territory of the city of Novi Sad. There are two parts of the questionnaire that refer to the subject of this research.

The first part of the questionnaire was related to the usual frequency of buying cured meat products on a monthly basis (less than once a month, once a month, several times a month, once a week, several times a week, daily). The second part of the questionnaire was in connection to the factors of the choice of a retailer where the largest number of purchases of cured meat products are being performed. These factors were identified according to the relevant literature and in consultations with managers from the industry. They include: appearance of the store, convenience, keeping promises, doing business in the right way, 
trust in employees, kindness and helpfulness, problem solving, quality of products, wide assortment, appropriate working hours, available parking space, giving savings cards, being close to place of living, favourable prices. Hereby, the factors were measured on five-point Likert-scale: from "strongly disagree" to "strongly agree".

\subsection{Procedures}

Firstly, respondents were divided into segments based on the usual frequency of buying cured meat products on a monthly basis. The respondents buying cured meat products less than once a month or once a month were described as low frequency segment. The respondents buying cured meat products several times a month or once a week were described as medium frequency segment. Finally, the respondents buying cured meat products several times a week or daily were described as high frequency segment.

For each of the segments all the factors of the choice of a retailer where the largest number of purchases of cured meat products are being performed were described by their mean value. It was compared to the mean value of all the respondents. The differences between those mean values for each of the factors were calculated. The ranks for the factors assessed in general, for the studied segment and for the absolute value of calculated differences were determined.

When respondents from different segments were compared regarding factors of the choice of a retailer, one-way ANOVA with Tukey post-hoc test was implemented.

\section{Results}

Table 1 shows the results regarding the frequency of buying cured meat products and established segments. It can be seen that nearly $30 \%$ of respondents perform such purchases several times a month or once a week making medium frequency segment the largest (nearly $60 \%$ of respondents). Similar result of almost $30 \%$ of respondents is performing purchases several times a week, comprising with $4.5 \%$ of respondents who are buying it daily, high frequency segment to which belong approximately every third respondent. Respondents buying cured meat less than once a month or once a month described as low frequency segment present less than $10 \%$ of the market.

Table 1. Frequency of buying cured meat products

\begin{tabular}{|c|c|c|c|}
\hline Frequency & $\begin{array}{c}\text { All } \\
\text { respondents }\end{array}$ & Segments & Percent \\
\hline less than once a month & $2.2 \%$ & \multirow{2}{*}{$\begin{array}{c}\text { Low } \\
\text { frequency }\end{array}$} & \multirow[t]{2}{*}{$8,2 \%$} \\
\hline once a month & $6.0 \%$ & & \\
\hline several times a month & $28.3 \%$ & \multirow{2}{*}{$\begin{array}{c}\text { Medium } \\
\text { frequency }\end{array}$} & \multirow[t]{2}{*}{$58,1 \%$} \\
\hline once a week & $29.8 \%$ & & \\
\hline several times a week & $29.2 \%$ & \multirow{2}{*}{$\begin{array}{c}\text { High } \\
\text { frequency }\end{array}$} & \multirow[t]{2}{*}{$33,7 \%$} \\
\hline daily & $4.5 \%$ & & \\
\hline
\end{tabular}

Source: Authors' analysis

Table 2 shows results regarding the retailer's choice in general as well as in the context of the low frequency segment. Generally, the choice of retailer is mostly influenced by its closeness to place of living (4.38), appropriate working hours (4.31), wide assortment (4.29), quality of products (4.24) and favourable prices (4.22). On the other hand, keeping promises (3.43) and giving savings cards (3.47) are the least important factors of such choice. 
Table 2. Factors of the choice of a retailer - the low frequency segment

\begin{tabular}{|c|c|c|c|c|c|c|}
\hline Factor & $\begin{array}{c}\text { Assessments } \\
\text { - all } \\
\text { respondents }\end{array}$ & Rank & $\begin{array}{c}\text { Assessments } \\
- \text { low } \\
\text { frequency } \\
\text { segment }\end{array}$ & Rank & Difference & Rank \\
\hline appearance of the store & 3.60 & 11 & 3.41 & 12 & -0.19 & 9 \\
\hline convenience & 3.93 & 7 & 3.62 & 8 & -0.31 & 4 \\
\hline keeping promises & 3.43 & 14 & 3.16 & 14 & -0.27 & 6 \\
\hline $\begin{array}{c}\text { doing business in the } \\
\text { right way }\end{array}$ & 3.62 & 10 & 3.35 & 13 & -0.27 & 7 \\
\hline $\begin{array}{c}\text { trust in employees } \\
\text { kindness and } \\
\text { helpfulness }\end{array}$ & 3.71 & 8 & 3.51 & 9 & -0.20 & 8 \\
\hline problem solving & 3.03 & 6 & 3.73 & 7 & -0.30 & 5 \\
\hline quality of products & 4.24 & 4 & 3.86 & 5 & -0.38 & 1 \\
\hline wide assortment & 4.29 & 3 & 3.95 & 4 & -0.34 & 3 \\
\hline $\begin{array}{c}\text { appropriate working } \\
\text { hours }\end{array}$ & 4.31 & 2 & 4.19 & 2 & -0.12 & 10 \\
\hline available parking space & 3.70 & 9 & 3.78 & 6 & 0.08 & 12 \\
\hline giving savings cards & 3.47 & 13 & 3.43 & 11 & -0.04 & 13 \\
\hline $\begin{array}{c}\text { being close to place of } \\
\text { living }\end{array}$ & 4.38 & 1 & 4.00 & 3 & -0.38 & 2 \\
\hline favourable prices & 4.22 & 5 & 4.22 & 1 & 0.00 & 14 \\
\hline \multicolumn{2}{|c|}{ Source: Authors' analysis } & & & \\
\hline
\end{tabular}

For low frequency segment, the five most influential factors are the same as in general, but not in the same order. Hereby, following assessments were obtained: favourable prices (4.22), appropriate working hours (4.19), closeness to place of living (4.00), wide assortment (3.95), quality of products (3.86). The least important factors are keeping promises (3.16) and doing business in the right way (3.35). Differences between low frequency segment and general results are almost always negative being the highest $(0.38)$ in the case of quality of products and closeness to place of living.

Table 3 presents results regarding the retailer's choice in general as well as in the context of the medium frequency segment.

Table 3. Factors of the choice of a retailer - the medium frequency segment

\begin{tabular}{|c|c|c|c|c|c|c|}
\hline Factor & $\begin{array}{c}\text { Assessments } \\
- \text { all } \\
\text { respondents }\end{array}$ & Rank & $\begin{array}{c}\text { Assessments - } \\
\text { medium } \\
\text { frequency } \\
\text { segment }\end{array}$ & Rank & Difference & Rank \\
\hline $\begin{array}{c}\text { appearance of the } \\
\text { store }\end{array}$ & 3.60 & 11 & 3.61 & 10 & 0.01 & 12 \\
\hline convenience & 3.93 & 7 & 3.93 & 7 & 0.00 & 14 \\
\hline keeping promises & 3.43 & 14 & 3.40 & 14 & -0.03 & 8 \\
\hline $\begin{array}{c}\text { doing business in the } \\
\text { right way }\end{array}$ & 3.62 & 10 & 3.58 & 12 & -0.04 & 5 \\
\hline trust in employees & 3.71 & 8 & 3.67 & 9 & -0.04 & 6 \\
\hline $\begin{array}{c}\text { kindness and } \\
\text { helpfulness }\end{array}$ & 4.03 & 6 & 4.07 & 6 & 0.04 & 7 \\
\hline problem solving & 3.58 & 12 & 3.50 & 13 & -0.08 & 3 \\
\hline quality of products & 4.24 & 4 & 4.23 & 5 & -0.01 & 13 \\
\hline wide assortment & 4.29 & 3 & 4.32 & 2 & 0.03 & 10 \\
\hline $\begin{array}{c}\text { appropriate working } \\
\text { hours }\end{array}$ & 4.31 & 2 & 4.28 & 3 & -0.03 & 11 \\
\hline
\end{tabular}




\begin{tabular}{|c|c|c|c|c|c|c|}
\hline $\begin{array}{c}\text { available parking } \\
\text { space }\end{array}$ & 3.70 & 9 & 3.80 & 8 & 0.10 & 2 \\
\hline giving savings cards & 3.47 & 13 & 3.60 & 11 & 0.13 & 1 \\
\hline $\begin{array}{c}\text { being close to place of } \\
\text { living }\end{array}$ & 4.38 & 1 & 4.41 & 1 & 0.03 & 9 \\
\hline favourable prices & 4.22 & 5 & 4.27 & 4 & 0.05 & 4 \\
\hline
\end{tabular}

Source: Authors' analysis

For medium frequency segment, the five most influential factors are also the same as in general, and also not in the same order. In the concrete case, following assessments were obtained: closeness to place of living (4.41), wide assortment (4.32), appropriate working hours (4.28), favourable prices (4.27), quality of products (4.23). The least important factors are keeping promises (3.40) and problem solving (3.50). The larges differences between medium frequency segment and general results are in the case of giving savings cards and available parking space.

Table 4 lists results regarding the retailer's choice in general as well as in the context of the high frequency segment.

Table 4. Factors of the choice of a retailer - the high frequency segment

\begin{tabular}{|c|c|c|c|c|c|c|}
\hline Factor & $\begin{array}{c}\text { Assessments } \\
- \text { all } \\
\text { respondents }\end{array}$ & Rank & $\begin{array}{c}\text { Assessments } \\
- \text { high } \\
\text { frequency } \\
\text { segment }\end{array}$ & Rank & Difference & Rank \\
\hline $\begin{array}{c}\text { appearance of the } \\
\text { store }\end{array}$ & 3.60 & 11 & 3.63 & 11 & 0.03 & 13 \\
\hline convenience & 3.93 & 7 & 3.99 & 7 & 0.06 & 10 \\
\hline keeping promises & 3.43 & 14 & 3.55 & 12 & 0.12 & 5 \\
\hline $\begin{array}{c}\text { doing business in the } \\
\text { right way }\end{array}$ & 3.62 & 10 & 3.75 & 9 & 0.13 & 4 \\
\hline $\begin{array}{c}\text { trust in employees } \\
\text { kindness and } \\
\text { helpfulness }\end{array}$ & 3.71 & 8 & 3.81 & 8 & 0.10 & 6 \\
\hline problem solving & 3.03 & 6 & 4.05 & 6 & 0.02 & 14 \\
\hline quality of products & 4.24 & 4 & 4.34 & 3 & 0.10 & 7 \\
\hline wide assortment & 4.29 & 3 & 4.32 & 4 & 0.03 & 12 \\
\hline $\begin{array}{c}\text { appropriate working } \\
\text { hours }\end{array}$ & 4.31 & 2 & 4.38 & 2 & 0.07 & 9 \\
\hline $\begin{array}{c}\text { available parking } \\
\text { space }\end{array}$ & 3.70 & 9 & 3.52 & 13 & -0.18 & 2 \\
\hline giving savings cards & 3.47 & 13 & 3.26 & 14 & -0.21 & 1 \\
\hline $\begin{array}{c}\text { being close to place of } \\
\text { living }\end{array}$ & 4.38 & 1 & 4.42 & 1 & 0.04 & 11 \\
\hline favourable prices & 4.22 & 5 & 4.13 & 5 & -0.09 & 8 \\
\hline
\end{tabular}

Source: Authors' analysis

And for high frequency segment, the five most influential factors are the same as in general, and in somewhat different order. In addition, following assessments were obtained: closeness to place of living (4.42), appropriate working hours (4.38), quality of products (4.34), wide assortment (4.32), favourable prices (4.13). The least important factors are giving saving cards (3.26) and available parking space (3.52). The larges differences between high frequency segment and general results are in the case of giving savings cards and available parking space.

Table 5 presents the results of the comparison between segments. 
Table 5. Factors of the choice of a retailer - comparison between segments

\begin{tabular}{|c|c|c|c|c|}
\hline Factor & $\begin{array}{c}\text { Assessments - } \\
\text { low frequency } \\
\text { segment }\end{array}$ & $\begin{array}{c}\text { Assessments - } \\
\text { medium } \\
\text { frequency } \\
\text { segment }\end{array}$ & $\begin{array}{c}\text { Assessments - } \\
\text { high } \\
\text { frequency } \\
\text { segment }\end{array}$ & Tests' results \\
\hline $\begin{array}{c}\text { appearance of the } \\
\text { store }\end{array}$ & 3.41 & 3.61 & 3.63 & $\begin{array}{l}\mathrm{F}(446)=0.60 ; \\
\mathrm{p}=0.55>0.05\end{array}$ \\
\hline convenience & 3.62 & 3.93 & 3.99 & $\begin{array}{l}F(446)=2.16 ; \\
p=0.12>0.05\end{array}$ \\
\hline keeping promises & 3.16 & 3.40 & 3.55 & $\begin{array}{l}F(446)=2.27 \\
p=0.11>0.05\end{array}$ \\
\hline $\begin{array}{l}\text { doing business in } \\
\text { the right way }\end{array}$ & 3.35 & 3.58 & 3.75 & $\begin{array}{l}F(446)=2.68 \\
p=0.07>0.05\end{array}$ \\
\hline trust in employees & 3.51 & 3.67 & 3.81 & $\begin{array}{l}\mathrm{F}(446)=1.50 \\
\mathrm{p}=0.23>0.05\end{array}$ \\
\hline $\begin{array}{l}\text { kindness and } \\
\text { helpfulness }\end{array}$ & 3.73 & 4.07 & 4.05 & $\begin{array}{l}F(446)=1.90 ; \\
p=0.15>0.05\end{array}$ \\
\hline problem solving & 3.49 & 3.50 & 3.73 & $\begin{array}{l}\mathrm{F}(446)=2.51 \\
\mathrm{p}=0.08>0.05\end{array}$ \\
\hline quality of products & 3.86 & 4.23 & 4.34 & $\begin{array}{c}\mathrm{F}(446)=5.95 ; \\
\mathrm{p}=0.00<0.05(1 \mathrm{st} \\
\text { and } 2 \mathrm{nd} ; 1 \mathrm{st} \text { and } \\
\text { 3rd })\end{array}$ \\
\hline wide assortment & 3.95 & 4.32 & 4.32 & $\begin{array}{c}\mathrm{F}(446)=3.28 \\
\mathrm{p}=0.04<0.05 \\
(1 \mathrm{st} \text { and } 2 \mathrm{nd} ; 1 \mathrm{st} \\
\text { and 3rd) }\end{array}$ \\
\hline $\begin{array}{c}\text { appropriate working } \\
\text { hours }\end{array}$ & 4.19 & 4.28 & 4.38 & $\begin{array}{l}F(446)=0.89 \\
p=0.41>0.05\end{array}$ \\
\hline $\begin{array}{c}\text { available parking } \\
\text { space }\end{array}$ & 3.78 & 3.80 & 3.52 & $\begin{array}{l}\mathrm{F}(446)=2.28 \\
\mathrm{p}=0.10>0.05\end{array}$ \\
\hline giving savings cards & 3.43 & 3.60 & 3.26 & $\begin{array}{l}F(446)=3.49 \\
p=0.03<0.05 \\
(2 \text { nd and 3rd) }\end{array}$ \\
\hline $\begin{array}{l}\text { being close to place } \\
\text { of living }\end{array}$ & 4.00 & 4.41 & 4.42 & $\begin{array}{c}\mathrm{F}(446)=3.75 \\
\mathrm{p}=0.02<0.05 \\
(1 \mathrm{st} \text { and } 2 \mathrm{nd} ; 1 \mathrm{st} \\
\text { and 3rd })\end{array}$ \\
\hline favourable prices & 4.22 & 4.27 & 4.13 & $\begin{array}{l}F(446)=1.31 \\
p=0.27>0.05\end{array}$ \\
\hline
\end{tabular}

Source: Authors' analysis

The results show that in the case of quality of products, wide assortment and closeness to place of living, the first segment differs in comparison to both, the second and the third segments. The average ratings are the lowest in the case of low frequency segment for all these factors. It should be noted that all three factors belong to top 5 most influential. In the case of giving saving cards, the medium frequency segment differs from the high frequency segment giving more importance to that factor.

\section{Discussion}

As many other sectors, cured meat production and sale can also be characterized by the increased competition. Therefore, manufacturers and retailers are struggling to attract as many consumers as possible, in order to achieve better business results. To accomplish 
these goals, the analysis of consumer behaviour can be of a great help. Its examination can provide very important information, which can be the basis for the decision making process. Because of this, there are many researches dedicated to consumer behaviour towards meat products. In this paper, the attention was paid to the frequency of buying cured meat products (less than once a month, once a month, several times a month, once a week, several times a week, daily), which was analysed from the aspect of factors associated to consumers store choosing (appearance of the store, convenience, keeping promises, doing business in the right way, trust in employees, kindness and helpfulness, problem solving, quality of products, wide assortment, appropriate working hours, available parking space, giving savings cards, being close to place of living, favourable prices).

Generally, as the obtained results have shown, the largest percent of respondents nearly $60 \%$ - belong to medium frequency segment, followed by high frequency segment (about one third of respondents) and low frequency segment (less than 10\%). Hereby, the choice of retailer is mostly influenced by its closeness to place of living, appropriate working hours, wide assortment, quality of products and favourable prices. Although those factors are not in the same order of relevance in the case of each segment (low, medium and high frequency), they belong to top 5 most influential factors in each of the cases. In addition, in the case of quality of products, wide assortment and closeness to place of living, the first segment significantly differs in comparison to both, the second and the third segments (the average ratings are the lowest in the case of that segment).

The research received no external funding.

\section{References}

1. OECD/FAO. (2019). OECD-FAO Agricultural Outlook 2019-2028. OECD Publishing, Paris/Food and Agriculture Organization of the United Nations, Rome, available at http://www.fao.org/3/ca4076en/ca4076en.pdf.

2. Clonan, A., Roberts, K.E., Holdsworth, M. (2016). Socioeconomic and demographic drivers of red and processed meat consumption: implications for health and environmental sustainability. Proceedings of the Nutrition Society, 75, 367- 373.

3. Sebranek, J., Bacus, J. (2007). Natural and organic cured meat products: regulatory, manufacturing, marketing, quality and safety issues. American meat science association white paper series, 1, 1-15.

4. Sych, J., Kaelin, I., Gerlach, F., Wróbel, A., Le, T., FitzGerald, R., Pestoni, G., Faeh, D., Krieger, J., Rohrmann, S. (2019). Intake of processed meat and association with sociodemographic and lifestyle factors in a representative sample of the swiss population. Nutrients, 11, 2556, 1-17.

5. Hung, Y., de Kok, T.M., Verbeke, W. (2016). Consumer attitude and purchase intention towards processed meat products with natural compounds and a reduced level of nitrite. Meat Science, 121, 119-126.

6. Issanchou, S. (1996). Consumer expectations and perceptions of meat and meat product quality. Meat Science, 43(S), 5-19.

7. Espejel, J., Fandos, C., Flavián, C. (2007). The role of intrinsic and extrinsic quality attributes on consumer behaviour for traditional food products. Managing Service Quality, 17(6), 681-701.

8. Hu, W. (2006). Exploring heterogeneity in consumers' meat store choices in an emerging market. Journal of Agribusiness, 24(2), 155-170. 
9. Souček, M., Turčínková, J. (2015). Factors for choosing a point of purchase of meat products. Acta universitatis agriculturae et silviculturae mendelianae brunensis, 63(2), 639-646.

10. Lavanya, S.M., Mahendran, K., Hemalatha, S., Senthilkumar, R. (2018). Assessment of relationship between service quality, consumer satisfaction and consumer loyalty in retail outlet using sem pls analysis. Asian Journal of Agricultural Extension, Economics \& Sociology, 25(2), 1-8. 